\title{
Effects of dietary $n-6: n-3$ PUFA ratio on fatty acid composition, free amino acid profile and gene expression of transporters in finishing pigs
}

\author{
Fengna $\mathrm{Li}^{1} \dagger$, Yehui Duan ${ }^{1,2} \dagger$, Yinghui $\mathrm{Li}^{1,2}$, Yulong Tang ${ }^{1}$, Meimei Geng ${ }^{1}$, Oso Abimbola Oladele ${ }^{3}$, \\ Sung Woo $\mathrm{Kim}^{4}$ and Yulong Yin ${ }^{1,5 *}$ \\ ${ }^{1}$ Scientific Observing and Experimental Station of Animal Nutrition and Feed Science in South-Central, Ministry of \\ Agriculture, Hunan Provincial Engineering Research Center of Healthy Livestock, Key Laboratory of Agro-ecological \\ Processes in Subtropical Region, Institute of Subtropical Agriculture, Chinese Academy of Sciences, Changsha Hunan \\ 410125, People's Republic of China \\ ${ }^{2}$ University of Chinese Academy of Sciences, Beijing 100039, People's Republic of China \\ ${ }^{3}$ Animal Nutrition Department, College of Animal Science and Livestock Production, Federal University of Agriculture, \\ PMB 2240 Abeokuta, Ogun State, Nigeria \\ ${ }^{4}$ Department of Animal Science, North Carolina State University, Raleigh, NC 27695, USA \\ ${ }^{5}$ Southwest Collaborative Innovation Center of Swine for Quality E Safety, \#211 Huiming Road, Wenjiang District, \\ Chengdu, People's Republic of China
}

(Submitted 6 June 2014 - Final revision received 12 September 2014 - Accepted 3 December 2014 - First published online 23 February 2015)

\section{Abstract}

Revealing the expression patterns of fatty acid and amino acid transporters as affected by dietary $n$ - $6: n$ - 3 PUFA ratio would be useful for further clarifying the importance of the balance between $n-6$ and $n-3$ PUFA. A total of ninety-six finishing pigs were fed one of four diets with the ratio of $1: 1,2 \cdot 5: 1,5: 1$ and 10:1. Pigs fed the dietary $n-6: n-3$ PUFA ratio of $5: 1$ had the highest $(P<0 \cdot 05)$ daily weight gain, and those fed the dietary $n-6: n-3$ PUFA ratio of $1: 1$ had the largest loin muscle area $(P<0 \cdot 01)$. The concentration of $n-3$ PUFA was raised as the ratio declined $(P<0.05)$ in the longissimus dorsi and subcutaneous adipose tissue. The contents of tryptophan, tasty amino acids and branchedchain amino acids in the longissimus dorsi were enhanced in pigs fed the dietary $n-6: n-3$ PUFA ratios of $1: 1-5: 1$. The mRNA expression level of the fatty acid transporter fatty acid transport protein-1 $(F A T P-1)$ was declined $(P<0 \cdot 05)$ in the longissimus dorsi of pigs fed the dietary $n$-6: $n$-3 PUFA ratios of $1: 1-5: 1$, and increased $(P<0 \cdot 05)$ in the subcutaneous adipose tissue of pigs fed the dietary $n$-6: $n$-3 PUFA ratios of 5:1 and 10:1. The expression profile of FATP-4 was similar to those of $F A T P-1$ in the adipose tissue. The mRNA expression level of the amino acid transceptors LAT1 and SNAT2 was up-regulated $(P<0 \cdot 05)$ in the longissimus dorsi of pigs fed the dietary $n$ - $6: n-3$ PUFA ratios of $1: 1$ and $2 \cdot 5: 1$. In conclusion, maintaining the dietary $n-6: n-3$ PUFA ratios of $1: 1-5: 1$ would facilitate the absorption and utilisation of fatty acids and free amino acids, and result in improved muscle and adipose composition.

Key words: $\boldsymbol{n}$-6:n-3 PUFA ratios: Fatty acids: Amino acids: Transporters: Finishing pigs

Fatty acids are essential components of membrane phospholipids. PUFA are classified into two series, $n-6$ and $n-3$ PUFA, based on their chemical structures. Animals and humans are unable to synthesise the essential $n$ - 3 fatty acids de novo, and so must obtain these fats from dietary sources. The conversion of linoleic acid $(18: 2 n-6)$ or $\alpha$-linolenic acid (18:3n-3) to long-chain PUFA shares a common enzymatic pathway (particularly for $\Delta 6$-desaturation), which is regarded as a rate-limiting step, hence there exists a competition between $n-6$ and $n-3$ fatty acids in vivo ${ }^{(1)}$. Thus, metabolism of both $n-6$ and $n-3$ PUFA must be taken into consideration. This concern is epidemiologically relevant because intakes of dietary $n$-6: $n$-3 PUFA ratio have been reported to exceed 10:1 over the past decades ${ }^{(2,3)}$. Normal body metabolism and functioning of the organs depends on maintaining a homeostatically balanced concentration of $n-6$ and $n-3$ PUFA $^{(4-7)}$, while excessive concentration of $n-6$ PUFA and an imbalance $n-6: n-3$ PUFA ratio have been associated with the development of cardiovascular, metabolic and neuropsychiatric disorders ${ }^{(8,9)}$. Further studies are, therefore,

\footnotetext{
Abbreviations: ACC, acetyl-CoA carboxylase; FATP, fatty acid transport proteins; HSL, hormone-sensitive lipase; LAT1, system L amino acid transporter 1; PAT, proton-assisted amino acid transporter; SNAT2, sodium-coupled neural amino acid transporter 2.
}

*Corresponding author: Y. Yin, email yinyulong@isa.ac.cn

† Both authors contributed equally to this work. 
required to investigate the $n-6: n-3$ PUFA ratio in ration for livestock animals so as to maintain an appropriate balance of the $n$-6:n-3 PUFA ratio in animal products, and, consequently, supply high-quality animal-derived foods and provide new insight to improve the health of humans.

Previous studies have shown that dietary PUFA affects the fatty acid profile of the resultant muscle and fat tissues ${ }^{(10)}$, and plays a vital role in the transport of fatty acids to many tissues via a protein-mediated mechanism ${ }^{(11)}$. A family of fatty acid transport proteins (FATP) is involved in the transport of fatty acids ${ }^{(12)}$. FATP are expressed in a tissue-specific pattern; for instance, FATP-1, -4 and -6 are co-expressed in muscle tissues ${ }^{(13,14)}$, but FATP-1 and FATP-4 are predominantly expressed in white adipose tissue ${ }^{(15)}$. Meanwhile, dietary PUFA composition promotes the hypertrophy of skeletal muscle ${ }^{(10)}$, thus it enhances the amounts of total protein or amino acids of the tissues. Importantly, amino acids have the capacity to transduce signals to metabolic pathways (e.g. mammalian target of rapamycin complex 1) via transporters and to changes in the intracellular concentration of specific amino acids that regulate muscle or adipose protein synthesis ${ }^{(16-18)}$. These transporters, also named 'transceptors', regulate the function of transporters and sensors, including system L amino acid transporter 1 (LAT1), protonassisted amino acid transporter (PAT) and sodium-coupled neural amino acid transporter 2 (SNAT2; for a review, see Suryawan \& Davis $\left.{ }^{(19)}\right)$. Therefore, in addition to the role as major substrates for energy production or protein synthesis, fatty acids and amino acids are involved in the modulation of structural and functional properties at the cellular level.

However, little is known about the effects of dietary $n-6: n-3$ PUFA ratio on the expression patterns of fatty acid and amino acid transporters. We previously reported that the $n-6: n-3$ PUFA ratio plays a key role in regulating lipid metabolism and inflammation in finishing pigs ${ }^{(20)}$. The purpose of the present study was to extend our previous studies, and investigate the effects of dietary $n-6: n-3$ PUFA ratio on fatty acid composition, free amino acid profile and gene expression patterns of fatty acid and amino acid transporters in the skeletal muscle and adipose tissues of finishing pigs. The present study seeks to provide consumers with high-quality animal food products containing an appropriate $n-6: n-3$ PUFA ratio, and ensure improved health status of humans.

\section{Materials and methods}

\section{Animals and experimental diets}

All procedures carried out in the present study were approved by the Animal Care Committee of the Institute of Subtropical Agriculture, the Chinese Academy of Sciences ${ }^{(21)}$. A total of ninety-six cross-bred (Large White $\times$ Landrace) male finishing pigs with a similar initial weight $(73.8$ (SEM 1.6) kg) were selected and assigned into four treatment groups in a completely randomised design. Each treatment was replicated six times with four pigs each. A maize-soyabean meal-based diet containing $3.00 \%$ linseed oil with no added soyabean oil was formulated to make a dietary $n-6: n-3$ PUFA ratio of 1:1 (diet 1). Also, three additional experimental diets were formulated such that 50,75 and 90\% equivalent amounts of linseed oil contained in diet 1 was replaced with soyabean oil to make a dietary $n-6: n-3$ PUFA ratio of $2 \cdot 5: 1$ (diet 2), 5:1 (diet 3) and 10:1 (diet 4), respectively. All the experimental diets were formulated to be isoenergetic and isonitrogenous and to meet the nutritional requirement of finishing pigs. Gross composition of the experimental diets is presented in online supplementary Table S1. Pigs were fed with the experimental diets ad libitum, and had unlimited access to clean drinking-water ${ }^{(22)}$. The experiment lasted for $60 \mathrm{~d}$.

\section{Sample collection}

Feed intake was recorded on a daily basis, while final body-weight gain was recorded on a weekly basis. The feed conversion ratio was computed as the feed consumed per unit weight gain $^{(23)}$. From each replicate, a pig with a representative weight was selected, fasted overnight and killed at the end of the feeding trial. Pigs were electrically stunned (250 V, 0.5 A, for 5-6 s), exsanguinated and eviscerated. Subsequently, samples (about $5 \mathrm{~g}$ ) of the longissimus dorsi muscle and subcutaneous adipose tissue were rapidly excised from the right side of the carcass. Visible intermuscular adipose tissue between muscles was carefully removed. The samples were then placed in liquid $\mathrm{N}_{2}$ and stored at $-80^{\circ} \mathrm{C}$ until further analyses ${ }^{(24,25)}$.

\section{Fatty acid composition}

Lipids were extracted from the longissimus dorsi muscle and subcutaneous adipose tissue samples by the chloroformmethanol (1:1, v/v) procedure. Fatty acid methyl esters were prepared for GC determination using $\mathrm{KOH} /$ methanol $^{(26)}$.

Fatty acid methyl esters were analysed using an Agilent 6890N gas chromatographer, equipped with a flame ionisation detector (Agilent Technologies). A CP-Sil 88 fused silica open tubular capillary column $(100 \mathrm{~m} \times 0 \cdot 25 \mathrm{~nm}$; Chrompack $)$ was used. The initial oven temperature was set at $45^{\circ} \mathrm{C}$ for $4 \mathrm{~min}$, and then raised to $175^{\circ} \mathrm{C}$ at $13^{\circ} \mathrm{C} / \mathrm{min}$, held at $175^{\circ} \mathrm{C}$ for $27 \mathrm{~min}$ and then increased to $215^{\circ} \mathrm{C}$ at $4{ }^{\circ} \mathrm{C} / \mathrm{min}$ and then held at $215^{\circ} \mathrm{C}$ for $35 \mathrm{~min}$. The injector and detector temperatures were set at $250^{\circ} \mathrm{C}$. The carrier gas was hydrogen at a flow rate of $30 \mathrm{ml} / \mathrm{min}$. Identification of individual fatty acid methyl esters was accomplished by the retention times of an authentic standard. The concentration of individual fatty acids was quantified according the peak area, and expressed as a percentage of total fatty acids ${ }^{(27)}$.

\section{Free amino acid profile}

Free amino acid profile was determined in the longissimus dorsi muscle. About $100 \mathrm{mg}$ samples were dissolved in water with methanol $(1: 1)$ at $4^{\circ} \mathrm{C}$ for $30 \mathrm{~min}$ and centrifuged at $10000 \mathrm{~g}$ for $10 \mathrm{~min}$, then the supernatant was filtered through glass wool and stored at $-80^{\circ} \mathrm{C}$ until analyses ${ }^{(28)}$. After centrifugation to separate soluble from insoluble material, $40 \mu \mathrm{l}$ of the supernatant were labelled with iTRAQ reagents (AA 45/32 kit; Applied Biosystems) as recommended by the manufacturer, and analysed on an Applied Biosystems 
3200 Q TRAP LC/MS/MS system equipped with a RP-C18 column (length $150 \mathrm{~mm}$, diameter $4.6 \mathrm{~mm}$ and particle size $5 \mathrm{~mm})^{(29)}$

\section{Quantitative real-time PCR analysis}

Total RNA was isolated from the muscle and adipose tissue using the RNeasy Mini Kit (Qiagen), according to the manufacturer's instructions. The quality and quantity of RNA were determined by ultraviolet spectroscopy using a NanoDrop ${ }^{\circledR}$ ND-1000 spectrophotometer (Thermo Fisher Scientific, Inc.). Thereafter, $1 \mu \mathrm{g}$ of total RNA was used to produce complementary DNA using an RT-PCR system (Promega) ${ }^{(30)}$. Primer sequences for selected genes are listed in Table 1. The relative expression levels of the target genes were determined by real-time PCR performed using an ABI7900HT PCR system (Applied Systems). Real-time PCR was performed in duplicate for each complementary DNA sample, using SYBR Green I as PCR core reagents in a final volume of $20 \mu \mathrm{l}$. PCR conditions were as follows: incubation for $10 \mathrm{~min}$ at $95^{\circ} \mathrm{C}$, followed by forty cycles of denaturation for $15 \mathrm{~s}$ at $95^{\circ} \mathrm{C}$, annealing and extension for $60 \mathrm{~s}$ at $56-64^{\circ} \mathrm{C}$. PCR amplification consisting of thirty-five cycles was conducted. mRNA expression levels of the target genes, expressed as arbitrary units, were acquired from the value of the threshold cycle $\left(C_{t}\right)$ of real-time PCR relative to that of $\beta$-actin using the comparative $C_{\mathrm{t}}$ method, according to the following formula:

$$
\begin{aligned}
2^{-\Delta \Delta C_{\mathrm{t}}}\left(\Delta \Delta C_{\mathrm{t}}=\right. & \left.C_{\mathrm{t} \text { gene of interest }}-C_{\mathrm{t} \beta \text {-actin }}\right)_{\text {treated }} \\
& -\left(C_{\mathrm{t} \text { gene of interest }}-C_{\mathrm{t} \beta \text {-actin }}\right)_{\text {untreated }}
\end{aligned}
$$

To normalise the expression levels of the target genes, the housekeeping gene $\beta$-actin was used as the internal control.

\begin{tabular}{|c|c|c|c|c|}
\hline Genes & Primers & Sequences $\left(5^{\prime}-3^{\prime}\right)$ & $\begin{array}{l}\text { Size } \\
\text { (bp) }\end{array}$ & $\begin{array}{c}T_{\mathrm{A}} \\
\left({ }^{\circ} \mathrm{C}\right)\end{array}$ \\
\hline \multirow[t]{2}{*}{$A C C$} & Forward & АTCССТССTTGССТСТССТА & 195 & 58 \\
\hline & Reverse & ACTTCCCGTTCAGATTTCCG & & \\
\hline \multirow[t]{2}{*}{$H S L$} & Forward & GCAGCATCTTCTTCCGCACA & 208 & 62 \\
\hline & Reverse & AGCCCTTGCGTAGAGTGACA & & \\
\hline \multirow[t]{2}{*}{ FATP-1 } & Forward & GGAGTAGAGGGCAAAGCAGG & 208 & 60 \\
\hline & Reverse & AGGTCTGGCGTGGGTCAAAG & & \\
\hline \multirow[t]{2}{*}{ FATP-4 } & Forward & TTCATCAAGACGGTCAGGCG & 133 & 58 \\
\hline & Reverse & AGACGGTGGCAGCGAATAAG & & \\
\hline \multirow[t]{2}{*}{ LAT1 } & Forward & TTTGTTATGCGGAACTGG & 155 & 61 \\
\hline & Reverse & AAAGGTGATGGCAATGAC & & \\
\hline \multirow[t]{2}{*}{ PAT1 } & Forward & TGTGGACTTCTTCCTGATTGTC & 125 & 58 \\
\hline & Reverse & CATTGTTGTGGCAGTTATTGGT & & \\
\hline \multirow[t]{2}{*}{ PAT2 } & Forward & GGGCTACTTGCGGTTCGG & 108 & 60 \\
\hline & Reverse & GCGCTTTGACACCTGGGAG & & \\
\hline \multirow[t]{2}{*}{ SNAT2 } & Forward & TACTTGGTTCTGCTGGTGTCC & 212 & 62 \\
\hline & Reverse & GTTGTGGGCTGTGTAAAGGTG & & \\
\hline \multirow[t]{2}{*}{$\beta$-Actin } & Forward & TGCGGGACATCAAGGAGAAG & 216 & 56 \\
\hline & Reverse & AGTTGAAGGTGGTCTCGTGG & & \\
\hline
\end{tabular}

Table 1. Primers used for real-time PCR

$T_{\mathrm{A}}$, annealing temperature; $A C C$, acetyl-CoA carboxylase; $H S L$, hormone-sensitive lipase; FATP, fatty acid transport proteins; $L A T 1$, system $L$ amino acid transporter 1; PAT, proton-assisted amino acid transporter; SNAT2, sodium-coupled neural amino acid transporter 2 .

\section{Statistical analysis}

All analyses were performed in triplicate. Data obtained were analysed using one-way ANOVA using the SAS 8.2 software package (SAS Institute, Inc.). Results are presented as means with their standard errors. Differences between significant mean values were compared using Duncan's multiple range test. Differences were considered significant at $P<0.05$.

\section{Results}

\section{Effects of dietary n-6:n-3 PUFA ratios on the growth performance and carcass traits of pigs}

The growth performance and carcass traits of pigs fed diets with varying $n-6: n-3$ PUFA ratios are presented in Table 2. Pigs fed the dietary $n-6: n-3$ PUFA ratio of 5:1 had the highest $(P<0.05)$ daily weight gain, while those fed the dietary $n-6$ : $n$-3 PUFA ratios of $1: 1,2 \cdot 5: 1$ and 10:1 exhibited low $(P<0.05)$ daily weight gain. The best $(P<0 \cdot 01)$ feed conversion ratio was obtained with pigs fed the dietary $n-6: n-3$ PUFA ratio of $5: 1$. Furthermore, the loin muscle area of pigs fed the dietary $n-6: n-3$ PUFA ratio of $1: 1$ was higher $(P<0.05)$ than those of pigs fed the dietary $n-6: n-3$ PUFA ratio of 10:1. The highest $(P<0.01)$ intramuscular fat was observed in pigs fed the dietary $n-6: n-3$ PUFA ratio of $2 \cdot 5: 1$. Pigs fed the dietary $n$-6:n-3 PUFA ratios of 5:1 and 10:1 had similar intramuscular fat with values higher $(P<0.01)$ than those obtained for pigs fed the dietary $n-6: n-3$ PUFA ratio of $1: 1$. However, the $n-6: n-3$ PUFA ratios had no effect $(P>0 \cdot 05)$ on backfat thickness.

\section{Effects of dietary n-6:n-3 PUFA ratios on tissue fatty acid profile}

The fatty acid profile of the longissimus dorsi muscle of pigs fed with the different dietary $n-6: n-3$ PUFA ratios is presented in Table 3. MUFA including 16:1 and 18:1 were unaffected $(P>0 \cdot 05)$ by the different dietary $n-6: n-3$ PUFA ratios. SFA including 14:0,16:0 and 18:0 were all enhanced $(P<0.05)$ in the longissimus dorsi muscles of pigs fed the dietary $n-6: n-3$ PUFA ratio of $2 \cdot 5: 1$. The concentrations of most PUFA such as $18: 3 n-3,20: 3 n-6,20: 4 n-6,20: 5 n-3,22: 5 n-3$ and $22: 6 n-3$ were highest $(P<0 \cdot 01)$ in pigs fed the dietary $n-6: n-3$ PUFA ratio of $1: 1$. However, the highest $(P<0 \cdot 05)$ value for $18: 2 n-6$ was obtained in the tissue of pigs fed with the dietary $n-6: n-3$ PUFA ratios of 5:1 and 10:1. Generally, the $n$-6:n-3 PUFA ratio in the longissimus dorsi muscle of pigs decreased $(P<0 \cdot 01)$ with decreasing dietary $n-6: n-3$ PUFA ratios.

The fatty acid profile of the subcutaneous adipose of pigs fed with the different dietary $n-6: n-3$ PUFA ratios is presented in Table 4 . The different dietary $n-6: n-3$ PUFA ratios had no effect $(P>0.05)$ on the adipose tissue concentrations of SFA and MUFA. The subcutaneous adipose tissue concentration of $16: 1$ was enhanced $(P<0 \cdot 01)$ in pigs fed the dietary $n-6: n-3$ PUFA ratios of $2 \cdot 5: 1, \quad 5: 1$ and $10: 1$. The least concentration was recorded for $16: 1,18: 1$ and $18: 2 n-6$ in the subcutaneous adipose tissue of pigs fed the dietary 
Table 2. Effects of dietary $n-6: n-3$ PUFA ratios on the growth performance and carcass trait of pigs (Mean values with their standard errors)

\begin{tabular}{|c|c|c|c|c|c|c|}
\hline \multirow[b]{2}{*}{ Items } & \multicolumn{4}{|c|}{$n-6: n-3$ PUFA ratio } & \multirow[b]{2}{*}{ SEM } & \multirow[b]{2}{*}{$P$} \\
\hline & $1: 1$ & $2 \cdot 5: 1$ & $5: 1$ & $10: 1$ & & \\
\hline Daily weight gain (kg) & $0.85^{\mathrm{b}}$ & $0.88^{b}$ & $0.93^{\mathrm{a}}$ & $0.87^{\mathrm{b}}$ & 0.01 & 0.02 \\
\hline Feed conversion rate $(G: F)$ & $3 \cdot 17^{\mathrm{a}}$ & $3 \cdot 15^{\mathrm{a}}$ & $2 \cdot 75^{\mathrm{b}}$ & $3 \cdot 18^{a}$ & 0.06 & $<0.01$ \\
\hline Backfat thickness (cm) & 3.23 & 3.46 & 3.53 & 3.55 & 0.12 & 0.32 \\
\hline Loin muscle area $\left(\mathrm{cm}^{2}\right)$ & $54 \cdot 87^{a}$ & $51 \cdot 32^{a, b}$ & $50 \cdot 64^{a, b}$ & $47 \cdot 32^{\mathrm{b}}$ & 1.46 & 0.04 \\
\hline Intramuscular fat (\%) & $1 \cdot 60^{\mathrm{C}}$ & $2 \cdot 90^{\mathrm{a}}$ & $2 \cdot 47^{\mathrm{b}}$ & $2 \cdot 33^{b}$ & 0.07 & $<0.01$ \\
\hline
\end{tabular}

$n$-6:n-3 PUFA ratio of $1: 1$. The content of $18: 2 n-6$ was greater in pigs fed the dietary $n-6: n-3$ PUFA ratios of $5: 1$ and $10: 1$ than in those fed the other two treatment diets. The content of $20: 3 n-6$ was also boosted in the group fed with the dietary $n-6: n-3$ PUFA ratio of $10: 1$. The contents of $18: 3 n-3,20: 4 n-6$, $20: 5 n-3$ and $22: 5 n-3$ were highest $(P<0 \cdot 05)$ in pigs fed the dietary $n-6: n-3$ PUFA ratio of $1: 1$. Consistent with the changes in the longissimus dorsi muscle, the ratio of $n-6: n-3$ PUFA in the adipose tissue also increased $(P<0.01)$ with increasing dietary $n-6: n-3$ PUFA ratio.

\section{Effects of dietary n-6:n-3 PUFA ratios on the free amino acid profile of longissimus dorsi muscle}

Free amino acids were determined in the longissimus dorsi muscle tissue, as detailed in Table 5 and Fig. 1. Tasty amino acids included alanine, glycine, glutamate and aspartic acids. The dietary treatments did not change the amount of alanine and glycine $(P>0.05)$. In addition, the concentration of glutamate in pigs fed the dietary $n-6: n-3$ PUFA ratio of $1: 1$ was enhanced compared with those fed the dietary n-6:n-3 PUFA ratio of $5: 1$. Aspartic acid concentration was also highest $(P<0.05)$ in pigs fed the dietary $n-6: n-3$ PUFA ratio of $2 \cdot 5: 1$ (Fig. 1(A)). Branched-chain amino acids included leucine, isoleucine and valine. The dietary treatments did not affect the concentration of isoleucine $(P>0 \cdot 05)$. A significant trend was observed for leucine $(P=0.06)$, with pigs fed the dietary $n$-6:n-3 PUFA ratio of $1: 1$ exhibiting the highest leucine concentration. Furthermore, reducing the dietary $n-6: n-3$ PUFA ratio (1:1) enhanced the content of $\alpha$-amino- $n$-butyric acid and carnosine $(P<0.05$; Fig. 1(B)). Ornithine concentration was highest in the tissue of pigs fed the dietary $n$-6:n-3 PUFA ratio of $2 \cdot 5: 1$. A similar trend was observed for tryptophan $(P=0 \cdot 06)$.

\section{Effects of dietary n-6:n-3 PUFA ratios on the gene expression levels of transporters}

To gain further insight into the different impacts of varying $n$-6:n-3 PUFA ratios on fatty acid and amino acid profiles, we investigated the effects of the dietary treatments on the relative mRNA expression levels of transporters and other key genes. In the longissimus dorsi muscle, no significant difference was observed for the mRNA expression level of hormone-sensitive lipase (HSL; P>0.05; Fig. 2(B)). However, the relative expression level of acetyl-CoA carboxylase (ACC) was up-regulated in pigs fed the dietary $n-6: n-3$ PUFA ratios of $1: 1$ and $2 \cdot 5: 1(P<0 \cdot 05$; Fig. 2(A)), and the expression level of FATP-1 was lowest in pigs fed the dietary $n-6: n-3$ PUFA ratio of 1:1 $(P<0 \cdot 05)$. However, no difference was observed for the expression level of FATP-4 (Fig. 3(A) and (B)). In the subcutaneous adipose, reducing the dietary $n-6: n-3$ PUFA ratio decreased the expression levels of $A C C$ and FATP-1 (Figs. 2(C) and $3(\mathrm{C})$, respectively), the expression level of $H S L$ was upregulated in pigs fed the dietary $n-6: n-3$ PUFA ratios of $1: 1$ and $2 \cdot 5: 1(P<0.05)$, and the expression pattern of FATP-4 was similar to that of FATP-1 (Figs. 2(D) and 3(D), respectively).

The dietary treatments did not change the relative mRNA expression levels of PAT1 and PAT2 in the longissimus dorsi muscle tissue of pigs (Fig. 4(B) and (C)). However, the expression level of LAT1 was higher in pigs fed the dietary $n-6: n-3$ PUFA ratio of $2 \cdot 5: 1$ than in those fed the dietary $n-6: n-3$ PUFA ratio of $10: 1$. Reducing the dietary $n-6: n-3$ PUFA ratio also enhanced the expression level of SNAT2 $(P<0 \cdot 05$; Fig. 4(A) and (D)).

Table 3. Effects of dietary $n-6: n-3$ PUFA ratios on the fatty acid profile of the longissimus dorsi muscle of pigs (\% of total fatty acids)

(Mean values with their standard errors)

\begin{tabular}{|c|c|c|c|c|c|c|}
\hline \multirow[b]{2}{*}{ Items } & \multicolumn{4}{|c|}{$n-6: n-3$ PUFA ratio } & \multirow[b]{2}{*}{ SEM } & \multirow[b]{2}{*}{$P$} \\
\hline & $1: 1$ & $2 \cdot 5: 1$ & $5: 1$ & 10:1 & & \\
\hline $14: 0$ & $0.77^{\mathrm{c}}$ & $1.08^{\mathrm{a}}$ & $0.97^{\mathrm{b}}$ & $1.01^{b}$ & 0.03 & $<0.01$ \\
\hline $16: 0$ & $24 \cdot 00^{b}$ & $25 \cdot 65^{\mathrm{a}}$ & $24 \cdot 44^{\mathrm{b}}$ & $24 \cdot 32^{\mathrm{b}}$ & 0.34 & 0.02 \\
\hline $16: 1$ & $2 \cdot 31$ & 2.40 & $2 \cdot 15$ & $2 \cdot 28$ & 1.00 & 0.20 \\
\hline $18: 0$ & $12 \cdot 29^{b}$ & $13 \cdot 42^{\mathrm{a}}$ & $12 \cdot 54^{\mathrm{b}}$ & $11.73^{c}$ & 0.19 & $<0.01$ \\
\hline $18: 1$ & $42 \cdot 27$ & $42 \cdot 77$ & 43.57 & 43.58 & 0.38 & 0.11 \\
\hline $18: 2 n-6$ & $11 \cdot 39^{\mathrm{b}}$ & $11.92^{b}$ & $13 \cdot 57^{\mathrm{a}}$ & $13.92^{\mathrm{a}}$ & 0.54 & 0.02 \\
\hline $18: 3 n-3$ & $1.51^{\mathrm{a}}$ & $0.83^{b}$ & $0.67^{c}$ & $0.61^{c}$ & 0.04 & $<0.01$ \\
\hline $20: 3 n-6$ & $0.33^{\mathrm{a}}$ & $0.15^{\mathrm{b}}$ & $0 \cdot 17^{\mathrm{b}}$ & $0.21^{\mathrm{b}}$ & 0.04 & 0.01 \\
\hline $20: 4 n-6$ & $2 \cdot 43^{a}$ & $0 \cdot 81^{c}$ & $1 \cdot 28^{b, c}$ & $1.88^{a, c}$ & 0.24 & $<0.01$ \\
\hline $20: 5 n-3$ & $0.60^{a}$ & $0.35^{\mathrm{b}}$ & $0.13^{\mathrm{C}}$ & $0.09^{c}$ & 0.05 & $<0.01$ \\
\hline $22: 5 n-3$ & $0.77^{a}$ & $0.45^{\mathrm{b}}$ & $0.33^{\mathrm{b}}$ & $0.21^{c}$ & 0.11 & $<0.01$ \\
\hline $22: 6 n-3$ & $1 \cdot 30^{\mathrm{a}}$ & $0.17^{\mathrm{b}}$ & $0.14^{\mathrm{b}}$ & $0.16^{b}$ & 1.00 & $<0.01$ \\
\hline $\mathrm{SFA}^{*}$ & $37.06^{b}$ & $40 \cdot 15^{\mathrm{a}}$ & $37 \cdot 96^{\mathrm{b}}$ & $37.06^{b}$ & 0.35 & $<0.01$ \\
\hline MUFA† & 44.58 & $45 \cdot 17$ & $45 \cdot 73$ & $45 \cdot 86$ & 0.43 & 0.31 \\
\hline PUFA & $18 \cdot 36^{a}$ & $14 \cdot 68^{b}$ & $16 \cdot 31^{a, b}$ & $17 \cdot 08^{a, b}$ & 0.63 & $<0.01$ \\
\hline$\sum n-6: \sum n-3 \S$ & $3.38^{\mathrm{d}}$ & $7 \cdot 16^{\mathrm{c}}$ & $11 \cdot 76^{\mathrm{b}}$ & $14.96^{\mathrm{a}}$ & 0.54 & $<0.01$ \\
\hline
\end{tabular}

a,b,c,d Mean values within a row with unlike superscript letters were significantly different $(P<0.05)$.

* $\mathrm{SFA}=14: 0+16: 0+18: 0$

†MUFA $=16: 1+18: 1$.

†PUFA $=18: 2+18: 3+20: 3+20: 4+20: 5+22: 5+22: 6$

$\S \sum n-6: \sum n-3=(18: 2+20: 3+20: 4):(18: 3+20: 5+22: 5+22: 6)$. 
Table 4. Effects of dietary $n-6: n-3$ PUFA ratios on the fatty acid profile of the subcutaneous adipose tissue of pigs (\% of total fatty acids) (Mean values with their standard errors)

\begin{tabular}{|c|c|c|c|c|c|c|}
\hline \multirow[b]{2}{*}{ Items } & \multicolumn{4}{|c|}{$n-6: n-3$ PUFA ratio } & \multirow[b]{2}{*}{ SEM } & \multirow[b]{2}{*}{$P$} \\
\hline & $1: 1$ & $2 \cdot 5: 1$ & $5: 1$ & $10: 1$ & & \\
\hline $14: 0$ & 0.89 & 0.98 & 0.98 & 0.90 & 0.04 & 0.21 \\
\hline $16: 0$ & $22 \cdot 91$ & 23.04 & $22 \cdot 95$ & 22.94 & 0.24 & 0.98 \\
\hline $16: 1$ & $1 \cdot 17^{b}$ & $1.90^{\mathrm{a}}$ & $2 \cdot 20^{\mathrm{a}}$ & $2.07^{a}$ & 0.15 & $<0.01$ \\
\hline $18: 0$ & $10 \cdot 92^{c}$ & $12 \cdot 11^{b}$ & $13 \cdot 21^{a}$ & $13.35^{\mathrm{a}}$ & 0.23 & $<0.01$ \\
\hline $18: 1$ & 41.85 & $42 \cdot 18$ & $42 \cdot 47$ & $42 \cdot 37$ & 0.28 & 0.50 \\
\hline $18: 2 n-6$ & $13 \cdot 14^{c}$ & $14 \cdot 85^{\mathrm{b}}$ & $16 \cdot 85^{\mathrm{a}}$ & $17.04^{\mathrm{a}}$ & 0.18 & $<0.01$ \\
\hline $18: 3 n-3$ & $8.54^{\mathrm{a}}$ & $4.44^{\mathrm{b}}$ & $0.87^{c}$ & $0.78^{c}$ & 0.25 & $<0.01$ \\
\hline $20: 3 n-6$ & $0.03^{\mathrm{c}}$ & $0.04^{c}$ & $0.14^{\mathrm{b}}$ & $0.22^{a}$ & 0.02 & $<0.01$ \\
\hline $20: 4 n-6$ & $0.15^{\mathrm{a}}$ & $0.15^{\mathrm{a}}$ & $0 \cdot 13^{\mathrm{b}}$ & $0 \cdot 13^{b}$ & 0.01 & $<0.01$ \\
\hline $20: 5 n-3$ & $0.13^{\mathrm{a}}$ & $0.08^{\mathrm{b}}$ & $0.06^{\mathrm{b}}$ & $0.04^{c}$ & 0.02 & 0.03 \\
\hline $22: 5 n-3$ & $0.28^{\mathrm{a}}$ & $0.24^{\mathrm{a}}$ & $0.14^{\mathrm{b}}$ & $0 \cdot 10^{\mathrm{b}}$ & 0.04 & 0.02 \\
\hline $22: 6 n-3$ & 0.03 & 0.03 & 0.03 & 0.02 & 0.003 & 0.23 \\
\hline $\mathrm{SFA}^{*}$ & 34.71 & $36 \cdot 11$ & $37 \cdot 13$ & 37.20 & 0.27 & 0.06 \\
\hline MUFA† & 43.01 & 44.07 & 44.66 & 44.45 & 0.32 & 0.20 \\
\hline PUFA & $22 \cdot 28^{\mathrm{a}}$ & $19 \cdot 82^{b}$ & $18 \cdot 21^{c}$ & $18 \cdot 35^{c}$ & 0.25 & $<0.01$ \\
\hline$\sum n-6: \sum n-3 \S$ & $1.48^{d}$ & $3 \cdot 14^{\mathrm{C}}$ & $15 \cdot 60^{\mathrm{b}}$ & $18 \cdot 43^{\mathrm{a}}$ & 0.45 & $<0.01$ \\
\hline
\end{tabular}

a,b,c,d Mean values within a row with unlike superscript letters were significantly different $(P<0.05)$.

${ }^{*} \mathrm{SFA}=14: 0+16: 0+18: 0$.

†MUFA $=16: 1+18: 1$.

‡PUFA $=18: 2+18: 3+20: 3+20: 4+20: 5+22: 5+22: 6$

$\S \sum n-6: \sum n-3=(18: 2+20: 3+20: 4):(18: 3+20: 5+22: 5+22: 6)$.

\section{Discussion}

There is an increasing awareness for the potential health benefits of the quantitative and qualitative characteristics of dietary fat, such as the ratio between $n-6$ and $n-3$ PUFA. The present study indicated that dietary $n-6: n-3$ PUFA ratios of 1:1-5:1 improved growth performance, loin muscle area and intramuscular fat percentage significantly, which is in agreement with previous reports ${ }^{(10)}$.

$n-3$ and $n$-6 PUFA are obtained through diet. Linoleic acid $(18: 2 n-6)$ is converted to $\gamma$-linolenic acid $(18: 3 n-6)$ and dihomo- $\gamma$-linolenic acid $(20: 3 n-6)$ to form the key intermediate arachidonic acid $(20: 4 n-6)$ by various enzymes. The $n$ - 3 fatty acid $\alpha$-linolenic acid $(18: 3 n-3)$ is converted to stearidonic acid (18:4n-3) and eicosatetraenoic acid (20:4n-3), which further metabolised to DHA (22:6n-3). Various lines of evidence in the past literature favour the importance of the $n-6: n-3$ PUFA ratio and support the view that decreasing the ratio leads to increased protection against degenerative diseases ${ }^{(31)}$. Previous studies have confirmed that reducing dietary $n-6$ and elevating $n-3$ PUFA is highly successful in raising the quantities of $18: 3 n-3$ and the longchain $n$-3 PUFA in pork, thus supplying valuable $n-3$ PUFA to the human diet ${ }^{(10,32)}$. Additionally, increasing dietary $n-3$ PUFA significantly enhances the relative content of $\alpha$-linolenic acid and long-chain $n-3$ fatty acids in the lipids of muscle and backfat at the expense of arachidonic acid ${ }^{(33)}$. In the present study, we also observed that long-chain $n-3$ and n-6:n-3 PUFA concentrations were markedly improved in the longissimus dorsi muscle and subcutaneous adipose tissue of pigs fed the dietary $n-6: n-3$ PUFA ratios of $1: 1$ and 2:5:1, and long-chain n-6 PUFA concentrations were reduced accordingly.
Long-chain n-3 PUFA have been found to affect protein metabolism in the neonatal pig. This means long-chain $n-3$ PUFA are potential regulators of protein metabolism in pigs $^{(34)}$. In addition, long-chain $n$-3 PUFA supplementation increased the muscle protein fractional synthesis rate, muscle protein concentration and the protein:DNA ratio via activating mammalian target of rapamycin signalling pathway in healthy older people ${ }^{(35)}$. Moreover, a diet enriched with $n$-3 PUFA has been shown to promote the hypertrophy of the longissimus dorsi muscle, quadriceps femoris muscle mass and semitendinosus muscle ${ }^{(10)}$. All these findings confirm that $n$-3 PUFA have a direct impact on muscle protein anabolism. Further studies have also provided information on the impact of fatty acids on muscle function. PUFA are able to enhance the proliferation and induce the differentiation of skeletal muscle cells through the activation of the key signalling pathway $^{(36)}$. n-3 PUFA significantly stimulate L6 skeletal muscle cell differentiation and membrane composition via activating mammalian target of rapamycin complex 1 signalling pathway $^{(37)}$. However, all these studies did not investigate the amino acid profile of the muscle tissue or cells. However, the present study indicated that concentrations of branchedchain amino acids including leucine and valine were highest in the longissimus dorsi muscle of pigs fed the dietary $n-6: n-3$ PUFA ratio of $1: 1$, and the concentrations of tasty amino acids including glutamate and aspartic acid were elevated in pigs fed the dietary $n-6: n-3$ PUFA ratios of $1: 1$ and $2 \cdot 5: 1$. Branched-chain amino acids could act as signalling molecules in the regulation of cellular processes through the modulation of intracellular cell signalling pathways, facilitating skeletal muscle protein anabolism ${ }^{(38)}$. However, tasty amino acids have been reported to be positively associated with meat flavour ${ }^{(39)}$.

Long-chain fatty acids comprise the main energy sources of the human body, requiring the synthesis of structural lipids. Central to the balance of lipid metabolism is the rate of long-chain fatty acid influx, efflux and metabolism by adipocytes in adipose tissue and intramuscular fat. As with glucose, fatty acids are also cleared from the circulation after a meal or when the demand for this substrate is needed ${ }^{(40)}$; however, it is unknown whether an increased rate of fatty acid uptake requires an elevated FATP expression level. In the present study, we observed that FATP-1 expression level was raised in the longissimus dorsi muscle of pigs fed the dietary $n-6: n-3$ PUFA ratio of 10:1, and the expression levels of both FATP-1 and FATP-4 were increased in pigs fed the dietary $n$-6:n-3 PUFA ratios of 5:1 and 10:1. FATP are a family of membrane-bound proteins that catalyse the ATP-dependent esterification of long-chain fatty acids and very-long-chain fatty acids to their acyl-CoA derivatives, and they have been shown to stimulate fatty acid transport ${ }^{(41)}$. The lipid carriers FATP-1 and FATP-4 are involved in the placental transfer of long-chain PUFA ${ }^{(42)}$, and the overexpression of FATP-1 and FATP-4 elevates cellular fatty acid uptake and acyl-CoA synthetases in adipocytes ${ }^{(43)}$. In addition, increasing skeletal muscle FATP-1 enhances the rate of long-chain fatty acid transport and channels, but not intramuscular lipid accumulation $^{(44)}$, and FATP-4 is apparently more important as a fatty 
Table 5. Effects of dietary $n-6: n-3$ PUFA ratios on the free amino acid profile of the longissimus dorsi muscle of pigs

(Mean values with their standard errors)

\begin{tabular}{|c|c|c|c|c|c|c|}
\hline \multirow[b]{2}{*}{ Items $(\mu \mathrm{g} / \mathrm{g})$} & \multicolumn{4}{|c|}{$n-6: n-3$ PUFA ratio } & \multirow[b]{2}{*}{ SEM } & \multirow[b]{2}{*}{$P$} \\
\hline & $1: 1$ & $2 \cdot 5: 1$ & $5: 1$ & $10: 1$ & & \\
\hline \multicolumn{7}{|l|}{ Essential amino acids } \\
\hline Arg & 2.98 & 2.99 & $2 \cdot 35$ & $3 \cdot 01$ & 0.17 & 0.23 \\
\hline His & $2 \cdot 49^{\mathrm{a}}$ & $2 \cdot 30^{a, b}$ & $1.42^{c}$ & $1 \cdot 84^{\mathrm{b}, \mathrm{c}}$ & 0.11 & $<0.01$ \\
\hline Ile & 0.28 & 0.32 & 0.28 & 0.22 & 0.09 & 0.61 \\
\hline Leu & $0.85^{a}$ & $0.69^{b}$ & $0.69^{b}$ & $0.64^{b}$ & 0.08 & 0.06 \\
\hline Lys & 0.75 & 0.84 & 0.86 & 0.92 & 0.08 & 0.79 \\
\hline Phe & 0.33 & 0.31 & 0.24 & 0.39 & 0.07 & 0.72 \\
\hline Thr & 1.02 & $1 \cdot 18$ & 1.02 & 1.38 & 0.20 & 0.78 \\
\hline Trp & $3 \cdot 18^{b}$ & $4 \cdot 45^{\mathrm{a}}$ & $2.97^{b}$ & $2 \cdot 86^{\mathrm{b}}$ & 0.27 & 0.06 \\
\hline Val & $0.40^{\mathrm{a}}$ & $0 \cdot 32^{a, b}$ & $0.27^{a, b}$ & $0.22^{b}$ & 0.03 & $<0.01$ \\
\hline \multicolumn{7}{|l|}{ Non-essential amino acids } \\
\hline Ala & $1 \cdot 17$ & $1 \cdot 34$ & $1 \cdot 12$ & 1.41 & $0 \cdot 20$ & 0.87 \\
\hline Asp & $1.03^{b}$ & $2.07^{\mathrm{a}}$ & $0.83^{b}$ & $0.96^{b}$ & 0.12 & $<0.01$ \\
\hline Glu & $1 \cdot 29^{a}$ & $0.93^{a, b}$ & $0.60^{b}$ & $0.93^{\mathrm{a}, \mathrm{b}}$ & 0.09 & 0.04 \\
\hline Gly & 1.49 & $1 \cdot 21$ & $1 \cdot 21$ & $1 \cdot 31$ & $0 \cdot 16$ & 0.31 \\
\hline Pro & 0.53 & 0.52 & 0.43 & 0.50 & 0.07 & 0.91 \\
\hline Ser & $2 \cdot 25$ & 1.43 & 1.99 & $2 \cdot 79$ & 0.35 & 0.34 \\
\hline Tyr & 0.84 & 0.94 & 0.86 & 0.47 & $0 \cdot 20$ & 0.66 \\
\hline \multicolumn{7}{|l|}{ Other amino acids } \\
\hline$\alpha$-Amino- $n$-butyric acid & $0.47^{\mathrm{a}}$ & $0.34^{b}$ & $0 \cdot 18^{c}$ & $0 \cdot 17^{\mathrm{c}}$ & 0.02 & $<0.01$ \\
\hline$\beta$-Amino-isobutyric acid & 0.20 & 0.20 & 0.21 & 0.23 & 0.03 & 0.96 \\
\hline$\beta$-Alanine & 3.59 & 3.05 & 3.04 & 3.41 & 0.15 & 0.27 \\
\hline Citrulline & $1 \cdot 27$ & 1.56 & 0.97 & 1.09 & 0.13 & 0.12 \\
\hline Carnosine & $22 \cdot 50^{\mathrm{a}}$ & $18 \cdot 07^{a, b}$ & $18 \cdot 73^{a, b}$ & $17.09^{b}$ & 0.12 & 0.04 \\
\hline Ethanolamine & 0.11 & 0.10 & 0.09 & 0.20 & 0.03 & 0.39 \\
\hline Ornithine & $1 \cdot 33^{b}$ & $2 \cdot 38^{\mathrm{a}}$ & $0.94^{b}$ & $0.99^{b}$ & 0.13 & $<0.01$ \\
\hline Taurine & $0.68^{a, b}$ & $0.82^{\mathrm{a}}$ & $0.59^{b}$ & $0.61^{b}$ & 0.09 & 0.05 \\
\hline
\end{tabular}

${ }^{a, b, c}$ Mean values within a row with unlike superscript letters were significantly different $(P<0.05)$.

acyl-CoA synthetase directing lipids for lipid metabolic pathways ${ }^{(45)}$. Therefore, both FATP-1 and FATP-4 facilitate the fatty acid metabolism of tissues, especially for skeletal muscle or adipose tissue. Meanwhile, we found that lower dietary $n-6: n-3$ PUFA enhanced the expression level of $A C C$ in the longissimus dorsi muscle, increased $H S L$ expression level but reduced $A C C$ expression level in subcutaneous adipose tissue. It is known that HSL and ACC are rate-limiting enzymes of lipid metabolism ${ }^{(46)}$. HSL is an intracellular enzyme that regulates the release of NEFA from lipid stores, and ACC is the key enzyme for the de novo biosynthesis of long-chain fatty acids. $n$-3 PUFA can enhance lipolysis through increasing the expression level of $H S L$ and decreasing the expression of $A C C^{(47)}$. Moreover, $n-3$ PUFA increases insulin sensitivity and then the activity of $\mathrm{HSL}^{(48)}$.

At present, the impact of PUFA on amino acid transporters is poorly understood and very little information exists. It is interesting to find that the mechanisms regulating the
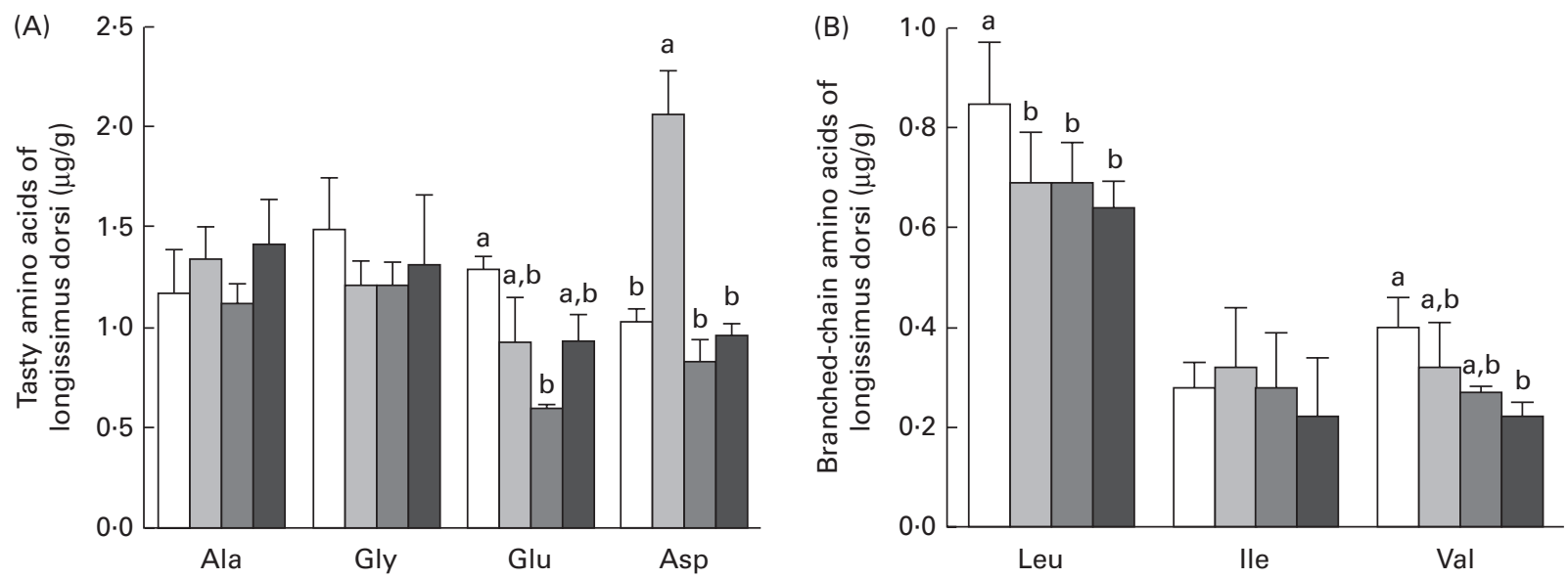

Fig. 1. Effects of different dietary $n-6: n-3$ PUFA ratios on (A) tasty amino acids and (B) branched-chain amino acid concentrations in the longissimus dorsi muscle of pigs. The growing-finishing pigs were fed one of the four isoenergetic diets with the $n-6: n-3$ PUFA ratios of 1:1 ( $\square$ ), $2 \cdot 5: 1$ ( $\square$ ), $5: 1$ ( $\square$ ) and 10:1 ( $\square$ ). Values are means, with their standard errors represented by vertical bars $(n 6)$. ${ }^{a}$ b Mean values with unlike letters were significantly different $(P<0 \cdot 05)$. 

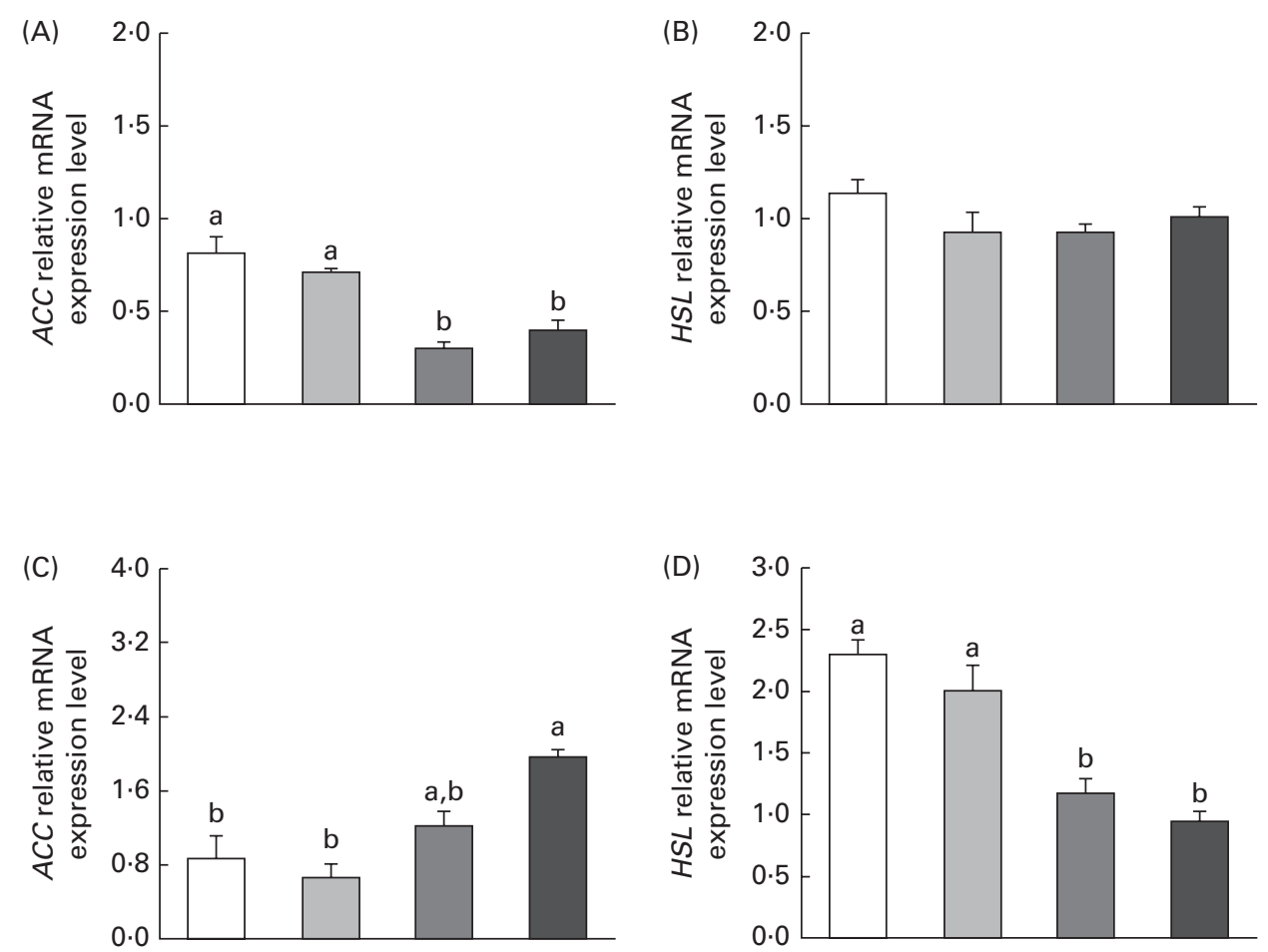

Fig. 2. Effects of different dietary $n-6: n-3$ PUFA ratios on the relative mRNA expression levels of acetyl-CoA carboxylase (ACC) and hormone-sensitive lipase $(H S L)$ in (A, B) the longissimus dorsi muscle and (C, D) subcutaneous adipose tissue of pigs. The growing-finishing pigs were fed one of the four isoenergetic

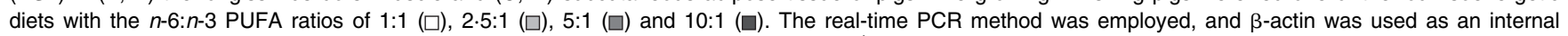
control. Values are means, with their standard errors represented by vertical bars $(n 6)$. ${ }^{\mathrm{a}, \mathrm{b}}$ Mean values with unlike letters were significantly different $(P<0.05)$.

abundance of amino acid transporters in the skeletal muscle in vivo. A previous study has reported that n-3 PUFA, especially DHA, modulate glutamate transporter subtypes via different mechanisms ${ }^{(49)}$, indicating that $n-3$ PUFA directly
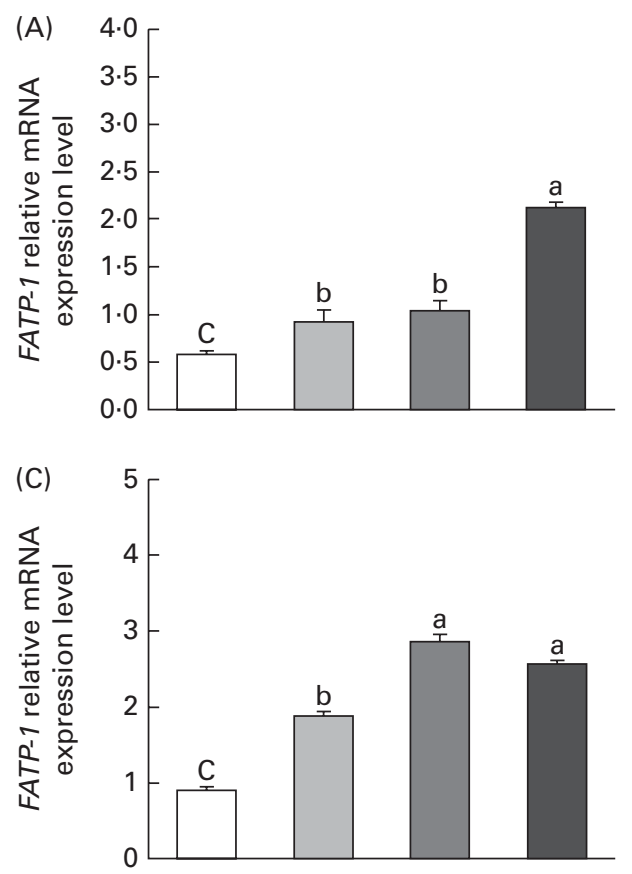

modulate various ion channels. The expression levels of amino acid transporters such as LAT1, PAT1 and SNAT2 are rapidly and transiently up-regulated following an increase in the availability of essential amino acids in the skeletal
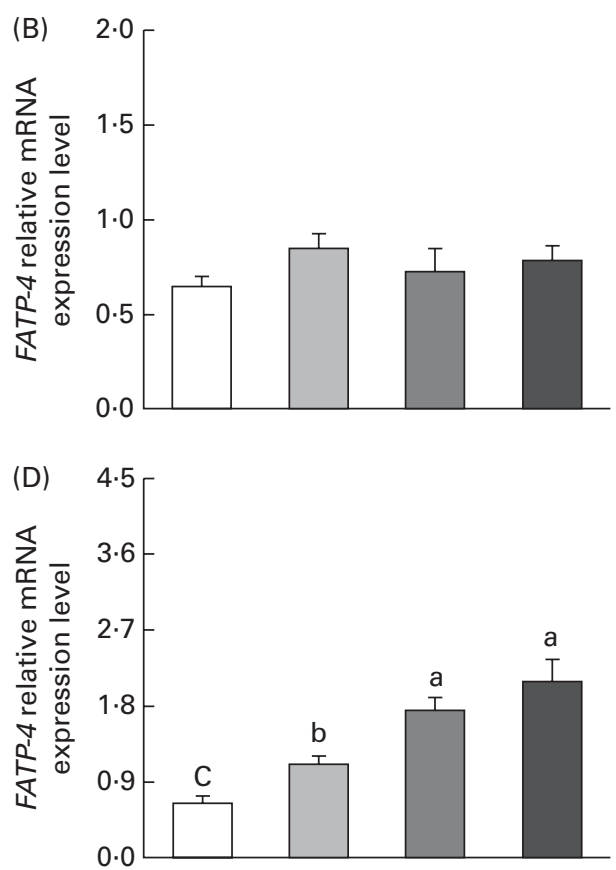

Fig. 3. Effects of different dietary $n-6: n-3$ PUFA ratios on the relative mRNA expression levels of fatty acid transport protein-1 (FATP-1) and FATP-4 in (A, B) the longissimus dorsi muscle and $(C, D)$ subcutaneous adipose tissue of pigs. The growing-finishing pigs were fed one of the four isoenergetic diets with the $n-6: n-3$

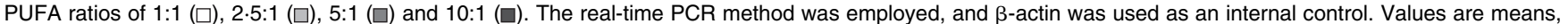
with their standard errors represented by vertical bars $(n 6)$. ${ }^{a, b}$ Mean values with unlike letters were significantly different $(P<0.05)$. 

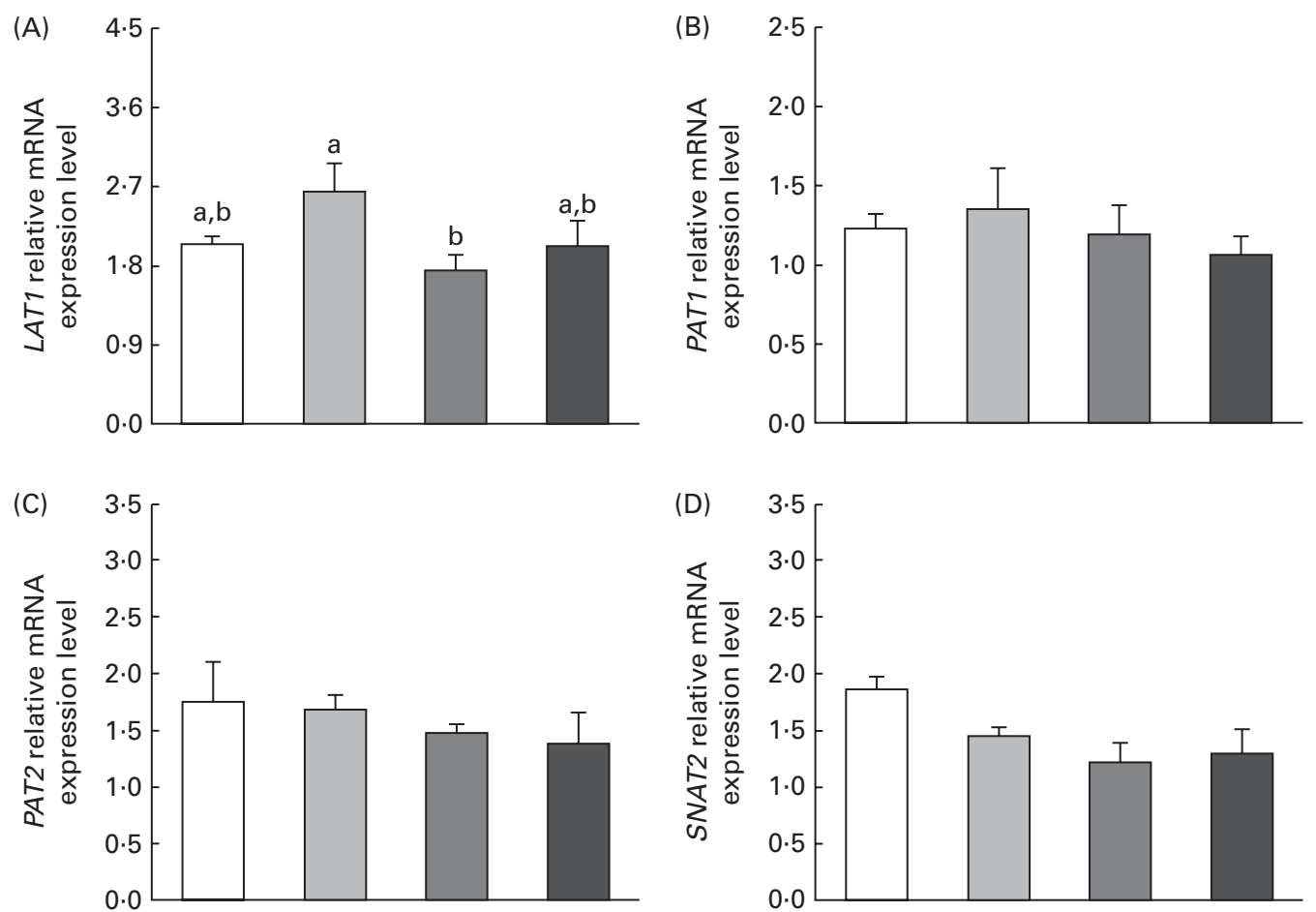

Fig. 4. Effects of different dietary $n-6: n-3$ PUFA ratios on the relative mRNA expression levels of (A) system L amino acid transporter 1 (LAT1), (B) proton-assisted amino acid transporter 1 (PAT1), (C) PAT2 and (D) sodium-coupled neural amino acid transporter 2 (SNAT2) in the longissimus dorsi muscle of pigs. The growing-finishing pigs were fed one of the four isoenergetic diets with the $n-6: n-3$ PUFA ratios of 1:1 ( $\square$ ), 2.5:1 ( $\square$ ), 5:1 ( $\square$ ) and 10:1 ( $\square$ ). The real-time PCR method was employed, and $\beta$-actin was used as an internal control. Values are means, with their standard errors represented by vertical bars ( $n$ 6). ${ }^{\mathrm{a}, \mathrm{b}}$ Mean values with unlike letters were significantly different $(P<0.05)$

muscle, and the increased expression levels of amino acid transporters may contribute to enhanced amino acid sensitivity $^{(50)}$. Our observations indicated that lower dietary $n-6: n-3$ PUFA up-regulated the expression levels of LAT1 and $S N A T 2$; however, no significant difference was observed for PAT1 and PAT2. SNAT2 is a principal isoform of the system A amino acid transporter and also a classical amino acid transceptor that is expressed in most extraneural tissues including skeletal muscle. An important role of SNAT2 and LAT1 is observed in the intracellular accumulation of essential amino acids, such as the branched-chain amino acid leucine, and the elevated abundance of SNAT2 and LAT1 is regulated in the skeletal muscle of neonatal pigs ${ }^{(51)}$. Generally, PAT families facilitate the transport of simple amino acids such as alanine, glycine and proline, and have potent effects on growth $^{(52)}$. However, there are few studies of PAT in mammalian species. PAT1 has been reported to function as part of the 'nutrisome' and to physically interact with the Rag-Ragulator complex ${ }^{(53)}$. The abundance of PAT2 is highly expressed in the skeletal muscle of neonatal pigs and developmentally regulated $^{(54)}$. These observations suggest the importance of transporter function in the uptake and metabolism of muscle and adipose tissue fatty acids and amino acids.

In conclusion, optimal n-6:n-3 PUFA, i.e. 1:1-5:1, modulated the fatty acid and free amino acid profile, and altered the expression levels of FATP-1 and FATP-4 and amino acid transceptor proteins LAT1 and SANT2. It also facilitated the absorption and utilisation of fatty acids and free amino acids, leading to an improved muscle:adipose ratio of the body. This will lead to the production of improved pork quality from the pig industry and, consequently, improved the health status of humans. Future studies are needed to explore the impact of the $n-6: n-3$ PUFA ratio on the crosstalk between skeletal muscle cells and adipocytes.

\section{Supplementary material}

To view supplementary material for this article, please visit http://dx.doi.org/10.1017/S0007114514004346

\section{Acknowledgements}

The present study was jointly supported by the National Basic Research Program of China (2012CB124704 and 2013CB127305), the National Nature Science Foundation of China (31372325, 31110103909 and 31330075) and the Chinese Academy of Sciences Visiting Professorships for Senior International Scientists (2013T2S0012).

The authors' contributions are as follows: Y. Y. and F. L. were in charge of the whole trial; F. L. and Y. D. wrote the manuscript; Y. L., Y. T. and M. G. assisted with the animal trial and biochemical analyses; S. W. K. and O. A. O. revised the manuscript.

The authors have no conflicts of interest to declare.

The Chinese Academy of Science STS Project (KFJ-EWSTS-063) 


\section{References}

1. Yamazaki K, Fujikawa M, Hamazaki T, et al. (1992) Comparison of the conversion rates of $\alpha$-linolenic acid (18:3(n-3)) and stearidonic acid (18:4(n-3)) to longer polyunsaturated fatty acids in rats. Biochimi Biophys Acta 1123, 18-26.

2. Astorg P, Arnault N, Czernichow S, et al. (2004) Dietary intakes and food sources of $n-6$ and $n-3$ PUFA in French adult men and women. Lipids 39, 527-535.

3. Blasbalg TL, Hibbeln JR, Ramsden CE, et al. (2011) Changes in consumption of omega- 3 and omega- 6 fatty acids in the United States during the 20th century. Am J Clin Nutr 93, 950-962.

4. Contreras MA \& Rapoport SI (2002) Recent studies on interactions between $n-3$ and $n-6$ polyunsaturated fatty acids in brain and other tissues. Curr Opin Lipidol 13, 267-272.

5. DeMar JC Jr, Ma K, Bell JM, et al. (2006) One generation of $n-3$ polyunsaturated fatty acid deprivation increases depression and aggression test scores in rats. J Lipid Res 47, 172-180.

6. Igarashi M, DeMar JC Jr, Ma K, et al. (2007) Upregulated liver conversion of $\alpha$-linolenic acid to docosahexaenoic acid in rats on a 15 week $n$-3 PUFA-deficient diet. J Lipid Res $\mathbf{4 8}$, $152-164$.

7. Igarashi M, Ma K, Chang L, et al. (2008) Rapoport, rat heart cannot synthesize docosahexaenoic acid from circulating $\alpha$-linolenic acid because it lacks elongase-2. J Lipid Res 49 , $1735-1745$.

8. Simopoulos AP (2002) The importance of the ratio of omega-6/omega-3 essential fatty acids. Biomed Pharmacother 56, 365-379.

9. Simopoulos AP (2008) The importance of the omega-6/ omega-3 fatty acid ratio in cardiovascular disease and other chronic diseases. Exp Biol Med (Maywood) 233, 674-688.

10. Huang FR, Zhan ZP, Luo J, et al. (2008) Duration of dietary linseed feeding affects the intramuscular fat, muscle mass and fatty acid composition in pig muscle. Livest Sci 118, $132-139$.

11. Bonen A, Chabowski A, Luiken JJ, et al. (2007) Is membrane transport of FFA mediated by lipid, protein, or both? Mechanisms and regulation of protein-mediated cellular fatty acid uptake: molecular, biochemical, and physiological evidence (invited review). Physiology (Bethesda) 22, 15-29.

12. DiRusso CC, Li H, Darwis D, et al. (2005) Comparative biochemical studies of the murine fatty acid transport proteins (FATP) expressed in yeast. J Biol Chem 280, $16829-16837$.

13. Gimeno RE, Ortegon AM, Patel S, et al. (2003) Characterization of a heart-specific fatty acid transport protein. $J$ Biol Chem 278, 16039-16044.

14. Doege H \& Stahl A (2006) Protein-mediated fatty acid uptake: novel insights from in vivo models. Physiology (Bethesda) 21, 259-268.

15. Lobo S, Wiczer BM, Smith AJ, et al. (2007) Fatty acid metabolism in adipocytes: functional analysis of fatty acid transport proteins 1 and 4. J Lipid Res 48, 609-620.

16. Yin YL, Yao K, Liu ZJ, et al. (2010) Supplementing L-leucine to a low-protein diet increases tissue protein synthesis in weanling pigs. Amino Acids 39, 1477-1486.

17. Li FN, Yin YL, Tan BE, et al. (2011) Leucine nutrition in animals and humans: mTOR signaling and beyond. Amino Acids 41, 1185-1193.

18. Duan YF, Li FN, Liu HG, et al. (2015) Nutritional and regulatory roles of leucine in muscle growth and fat reduction. Front Biosci (Landmark Ed) 20, 796-813.
19. Suryawan A \& Davis TA (2011) Regulation of protein synthesis by amino acids in muscle of neonates. Front Biosci (Landmark Ed) 16, 1445-1460.

20. Duan Y, Li F, Li L, et al. (2014) n-6:n-3 PUFA ratio is involved in regulating lipid metabolism and inflammation in pigs. $\mathrm{BrJ}$ Nutr 111, 445-451.

21. Deng D, Yao K, Chu WY, et al. (2009) Impaired translation initiation activation and reduced protein synthesis in weaned piglets fed a low-protein diet. J Nutr Biochem 20, $544-552$.

22. Wu X, Yin YL, Li TJ, et al. (2010) Dietary supplementation with L-arginine or $N$-carbamylglutamate enhances intestinal growth and heat shock protein-70 expression in weanling pigs fed a corn- and soybean meal-based diet. Amino Acids 39, 831-839.

23. Li X, Xiong H, Yang K, et al. (2011) Effects of rice dreg protein and its hydrolysate on growth performance and small intestine morphology of early-weaned rats. J Sci Food Agric 91, 687-693.

24. Tan B, Yin YL, Liu ZQ, et al. (2008) Dietary L-arginine supplementation increases muscle gain and reduces body fat mass in growing-finishing pigs. Amino Acids 27, 169-175.

25. Tan BE, Li XG, Kong XF, et al. (2009) Dietary L-arginine supplementation enhances the immune status in early-weaned piglets. Amino Acids 37, 323-331.

26. Demirel G, Wachira AM, Sinclair LA, et al. (2004) Effects of dietary $n-3$ polyunsaturated fatty acids, breed and dietary vitamin $\mathrm{E}$ on the fatty acids of lamb muscle, liver and adipose tissue. BrJ Nutr 91, 551-565.

27. Yin YL, McEvoy J, Souffrant WB, et al. (2000) Apparent digestibility (ileal and overall) of nutrients and endogenous nitrogen losses in growing pigs fed wheat or wheat by-products without or with xylanase supplementation. Livest Prod Sci 62, 119-132.

28. Ren WK, Yin J, Wu MM, et al. (2014) Serum amino acids profile and the beneficial effects of L-arginine or L-glutamine supplementation in dextran sulfate sodium colitis. PLOS ONE 9, e88335.

29. Sales F, Pacheco D, Blair H, et al. (2013) Muscle free amino acid profiles are related to differences in skeletal muscle growth between single and twin ovine fetuses near term. Springerplus 2, 483.

30. Ren WK, Chen S, Yin J, et al. (2014) Dietary arginine supplementation of mice alters the microbial population and activates intestinal innate immunity. J Nutr 144, 568-579.

31. Russo GL (2009) Dietary $n-6$ and $n-3$ polyunsaturated fatty acids: from biochemistry to clinical implications in cardiovascular prevention. Biochem Pharmacol 77, 937-946.

32. Enser M, Richardson RI, Wood JD, et al. (2000) Feeding linseed to increase the $n-3$ PUFA of pork: fatty acid composition of muscle, adipose tissue, liver and sausages. Meat Sci 55, 201-212.

33. Nuernberg K, Fischer K, Nuernberg G, et al. (2005) Effects of dietary olive and linseed oil on lipid composition, meat quality, sensory characteristics and muscle structure in pigs. Meat Sci 70, 63-74.

34. Bergeron K, Julien P, Davis TA, et al. (2007) Long-chain n-3 fatty acids enhance neonatal insulin-regulated protein metabolism in piglets by differentially altering muscle lipid composition. J Lipid Res 48, 2396-2410.

35. Smith GI, Atherton P, Reeds DN, et al. (2011) Dietary omega-3 fatty acid supplementation increases the rate of muscle protein synthesis in older adults: a randomized controlled trial. Am J Clin Nutr 93, 402-412. 
36. Lee JH, Tachibana H, Morinaga Y, et al. (2009) Modulation of proliferation and differentiation of $\mathrm{C} 2 \mathrm{C} 12$ skeletal muscle cells by fatty acids. Life Sci $\mathbf{8 4}, 415-420$.

37. Briolay A, Jaafar R, Nemoz G, et al. (2013) Myogenic differentiation and lipid-raft composition of L6 skeletal muscle cells are modulated by PUFAs. Biochim Biophys Acta 1828, 602-613.

38. Rennie MJ, Bohé J, Smith K, et al. (2006) Branched-chain amino acids as fuels and anabolic signals in human muscle. J Nutr 136, Suppl. 1, 264S-268S.

39. Troy D, Pearce R, Byrne B, et al. (2006) 52nd International Congress of Meat Science and Technology. Wageningen: Wageningen Academic Publishers.

40. Bickerton AS, Roberts R, Fielding BA, et al. (2007) Preferential uptake of dietary fatty acids in adipose tissue and muscle in the postprandial period. Diabetes 56, 168-176.

41. Hall AM, Smith AJ \& Bernlohr DA (2003) Characterization of the acyl-CoA synthetase activity of purified murine fatty acid transport protein 1. J Biol Chem 278, 43008-43013.

42. Larqué E, Krauss-Etschmann S, Campoy C, et al. (2006) Docosahexaenoic acid supply in pregnancy affects placental expression of fatty acid transport proteins. Am J Clin Nutr $\mathbf{8 4}$, 853-861.

43. Zhan T, Poppelreuther M, Ehehalt R, et al. (2012) Overexpressed FATP1, ACSVL4/FATP4 and ACSL1 increase the cellular fatty acid uptake of 3T3-L1 adipocytes but are localized on intracellular membranes. PlOS ONE 7, e45087.

44. Sebastián D, Guitart M, García-Martínez C, et al. (2009) Novel role of FATP1 in mitochondrial fatty acid oxidation in skeletal muscle cells. J Lipid Res 50, 1789-1799.

45. Jeppesen J, Jordy AB, Sjøberg KA, et al. (2012) Enhanced fatty acid oxidation and FATP 4 protein expression after endurance exercise training in human skeletal muscle. PLOS ONE 7, e29391.
46. Numa S, Nakanishi S, Hashimoto T, et al. (1970) Role of acetyl-coenzyme A carboxylase in the control of fatty acid synthesis. Vitam Horm 28, 213-243.

47. Wang YC, Kuo WH, Chen CY, et al. (2010) Docosahexaenoic acid regulates serum amyloid A protein to promote lipolysis through down regulation of perilipin. J Nutr Biochem 21, 317-324.

48. Badin PM, Louche K, Mairal A, et al. (2011) Altered skeletal muscle lipase expression and activity contribute to insulin resistance in humans. Diabetes 60, 1734-1742.

49. Berry CB, Hayes D, Murphy A, et al. (2005) Differential modulation of the glutamate transporters GLT1, GLAST and EAAC1 by docosahexaenoic acid. Brain Res 1037, $123-133$.

50. Drummond MJ, Fry CS, Glynn EL, et al. (2011) Skeletal muscle amino acid transporter expression is increased in young and older adults following resistance exercise. $J$ Appl Physiol 111, 135-142.

51. Suryawan A, Gazzaneo MC, Almonaci RD, et al. (2010) SNAT2 and LAT1 transporter abundance is developmentally regulated in skeletal muscle of neonatal pigs. FASEB J 24, (Meeting Abstract Supplement) 331.4.

52. Goberdhan DC, Meredith D, Boyd CA, et al. (2005) PAT-related amino acid transporters regulate growth via a novel mechanism that does not require bulk transport of amino acids. Development 132, 2365-2375.

53. Ögmundsdóttir MH, Heublein S, Kazi S, et al. (2012) Protonassisted amino acid transporter PAT1 complexes with Rag GTPases and activates TORC1 on late endosomal and lysosomal membranes. PlOS ONE 7, e36616.

54. Suryawan A \& Davis TA (2010) Abundance and activation of mTORC1 regulators in skeletal muscle of neonatal pigs are modulated by insulin, amino acids, and age. J Appl Physiol 109, 1448-1454. 